\title{
Acute effect of amiodarone on cardiovascular reflexes of normotensive and renal hypertensive rats
}

P.F. Oliveira ${ }^{1}$, V.J. Dias da Silva ${ }^{3}$, M.C.O. Salgado ${ }^{2}$, R. Fazan Jr. ${ }^{1}$, C.A. Aguiar ${ }^{1}$ and H.C. Salgado ${ }^{1}$

\author{
${ }^{1}$ Departamento de Fisiologia, ${ }^{2}$ Departamento de Farmacologia, \\ Faculdade de Medicina de Ribeirão Preto, Universidade de São Paulo, \\ Ribeirão Preto, SP, Brasil \\ ${ }^{3}$ Departamento de Ciências Biológicas, Faculdade de Medicina do Triângulo Mineiro, \\ Uberaba, MG, Brasil
}

\author{
Correspondence \\ H.C. Salgado \\ Departamento de Fisiologia \\ FMRP, USP \\ Av. Bandeirantes, 3900 \\ 14049-900 Ribeirão Preto, SP \\ Brasil \\ Fax: +55-16-633-0017 \\ E-mail: hcsalgad@fmrp.usp.br \\ Presented at the VIII Brazilian \\ Symposium on Cardiovascular \\ Physiology, São Paulo, SP, Brazil, \\ June 4-6, 2004. \\ Research supported by PRONEX I, \\ FAPESP and CNPq.
}

Received August 16, 2004 Accepted March 22, 2005

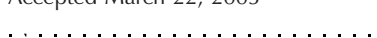

\begin{abstract}
The aim of the present study was to evaluate the effect of amiodarone on mean arterial pressure (MAP), heart rate (HR), baroreflex, BezoldJarisch, and peripheral chemoreflex in normotensive and chronic onekidney, one-clip (1K1C) hypertensive rats $(\mathrm{N}=9$ to 11 rats in each group). Amiodarone $(50 \mathrm{mg} / \mathrm{kg}, i \mathrm{v}$ ) elicited hypotension and bradycardia in normotensive $(-10 \pm 1 \mathrm{mmHg},-57 \pm 6 \mathrm{bpm})$ and hypertensive rats $(-37 \pm 7 \mathrm{mmHg},-39 \pm 19 \mathrm{bpm})$. The baroreflex index $(\Delta \mathrm{HR} /$ $\triangle \mathrm{MAP})$ was significantly attenuated by amiodarone in both normotensive $(-0.61 \pm 0.12 v s-1.47 \pm 0.14 \mathrm{bpm} / \mathrm{mmHg}$ for reflex bradycardia and $-1.15 \pm 0.19 v s-2.63 \pm 0.26 \mathrm{bpm} / \mathrm{mmHg}$ for reflex tachycardia) and hypertensive rats $(-0.26 \pm 0.05 v s-0.72 \pm 0.16 \mathrm{bpm} / \mathrm{mmHg}$ for reflex bradycardia and $-0.92 \pm 0.19 v s-1.51 \pm 0.19 \mathrm{bpm} / \mathrm{mmHg}$ for reflex tachycardia). The slope of linear regression from $\Delta$ pulse inter$\mathrm{val} / \triangle \mathrm{MAP}$ was attenuated for both reflex bradycardia and tachycardia in normotensive rats $(-0.47 \pm 0.13 v s-0.94 \pm 0.19 \mathrm{~ms} / \mathrm{mmHg}$ and -0.80 $\pm 0.13 v s-1.11 \pm 0.13 \mathrm{~ms} / \mathrm{mmHg}$ ), but only for reflex bradycardia in hypertensive rats $(-0.15 \pm 0.02 v s-0.23 \pm 0.3 \mathrm{~ms} / \mathrm{mmHg})$. In addition, the MAP and HR responses to the Bezold-Jarisch reflex were 20-30\% smaller in amiodarone-treated normotensive or hypertensive rats. The bradycardic response to peripheral chemoreflex activation with intravenous potassium cyanide was also attenuated by amiodarone in both normotensive $(-30 \pm 6 v s-49 \pm 8 \mathrm{bpm})$ and hypertensive rats $(-34 \pm 13$ $v s-42 \pm 10 \mathrm{bpm})$. On the basis of the well-known electrophysiological effects of amiodarone, the sinus node might be the responsible for the attenuation of the cardiovascular reflexes found in the present study.
\end{abstract}

\section{Introduction}

Amiodarone is a drug classified as a class III antiarrhythmic due to blockage of potassium channels, which lengthens the cardiac
Key words

- Amiodarone

- Baroreflex

- Bezold-Jarisch reflex

- Chemoreflex

- Autonomic nervous system

- 1K1C hypertension 
patholytic action (4) have been identified in the action of amiodarone. Because of these actions, amiodarone has been widely used for the acute and chronic treatment of ventricular and supraventricular arrhythmia (5-7). The mechanisms of these antiarrhythmic actions of amiodarone, however, are somewhat complex and are poorly understood. In addition to these electrophysiological effects, a recent study reported that intravenous amiodarone increased the efferent vagal discharge and decreased the sympathetic activity to the heart of normotensive rats (8). Moreover, it has been demonstrated that intravenous amiodarone modified autonomic balance and increased baroreflex sensitivity in both normotensive and spontaneously hypertensive rats (SHR) (9). Nevertheless, there are no data reporting the effect of amiodarone on any other model of hypertension.

Chronic one-kidney, one-clip (1K1C) hypertension is an experimental model extensively studied in rats (10). This model is characterized by an initial rise in arterial pressure (AP) triggered by increased plasma renin activity and fluid volume expansion, followed by a chronic increase in peripheral and central sympathetic activity that appears to contribute significantly to the maintenance of hypertension $(10,11)$. In addition, it has been well documented that this hypertensive model exhibits a depressed cardiac baroreflex (12).

Therefore, the objective of the present study was to examine the following aspects in conscious $1 \mathrm{~K} 1 \mathrm{C}$ hypertensive rats: 1 ) the hemodynamic effects of amiodarone, and 2) the role played by amiodarone in cardiovascular reflexes, i.e., the baroreflex control of heart rate (HR), Bezold-Jarisch reflex and peripheral chemoreflex.

\section{Material and Methods}

\section{Animals and surgical procedures}

Experiments were performed on con- scious normotensive and chronic (4 weeks) $1 \mathrm{~K} 1 \mathrm{C}$ hypertensive male Wistar rats weighing 300-350 g. The normotensive groups consisted of 9 animals which received vehicle and 9 animals which received amiodarone, while the $1 \mathrm{~K} 1 \mathrm{C}$ hypertensive groups consisted of 9 animals which received vehicle and 11 animals which received amiodarone.

1K1C hypertension was produced by partial constriction of the main left renal artery with a silver clip (gap of $0.20 \mathrm{~mm}$ ) followed by contralateral nephrectomy according to the technique adapted by Schaffenburg (13) to small animals. After surgery, $1 \mathrm{~K} 1 \mathrm{C}$ hypertensive animals were housed in cages with free access to tap water and kept in a room with a 12-h light/dark cycle. The experimental protocols were started 4 weeks after surgery for the induction of hypertension.

Twenty-four hours before the experiment, under anesthesia with 99\% 2,2,2 tribromoethanol $(250 \mathrm{mg} / \mathrm{kg}$, ip $)$, catheters were placed into the left femoral artery and vein for direct measurement of AP and for drug administration, and exteriorized on the back of the animal. Next day, the arterial catheter was connected to a strain-gauge transducer (P10Ez; Spectramed, Oxnard, CA, USA) for AP recordings. The signal was amplified (Stoelting, Wood Dale, IL, USA) and continuously sampled $(1 \mathrm{kHz})$ with an IBM/PC equipped with a 12-bit analog-to-digital interface (CAD 12/36 Lynx Tecnologia Eletrônica, São Paulo, SP, Brazil). Systolic, diastolic and mean arterial pressure (MAP, $\mathrm{mmHg}$ ), as well as HR and pulse interval (PI) were calculated from pressure waveforms using a computer software (Windaq/ CODAS; Dataq Instruments, Akron, OH, USA).

Intravenous administration of amiodarone or vehicle

Amiodarone (amiodarone hydrochloride; 
Galena Química e Farmacêutica Ltda., Campinas, SP, Brazil) was dissolved in a vehicle solution consisting of a mixture $(1: 1: 8)$ of polysorbate 80 (Tween 80 ; Sigma, St. Louis, MO, USA), ethanol (Merck S.A., Rio de Janeiro, RJ, Brazil) and distilled water. An amiodarone dose of $50 \mathrm{mg} / \mathrm{kg}$ was administered $i v$ in a volume of $1 \mathrm{~mL} / \mathrm{kg}$, and was chosen on the basis of pharmacokinetic and pharmacodynamic studies in rats $(4,14)$.

\section{Experimental protocol}

The protocol consisted of 20 min of basal recording followed by $i v$ administration of amiodarone or vehicle. After stabilization of AP and HR ( 15 min after amiodarone or vehicle) the pharmacological stimulation of baroreflex, Bezold-Jarisch reflex and peripheral chemoreflex was performed. All drugs used to stimulate the cardiovascular reflexes were injected in a small volume corresponding to $0.1 \mathrm{~mL} / \mathrm{kg}$.

Reflex variations in HR were elicited by changes in MAP induced by bolus injection of a single dose of phenylephrine $(4 \mu \mathrm{g} / \mathrm{kg}$, $i v)$ or sodium nitroprusside $(8 \mu \mathrm{g} / \mathrm{kg}, i v)$. Baroreflex sensitivity was assessed as follows: 1) the baroreflex index was calculated as the $\Delta \mathrm{HR} / \triangle \mathrm{MAP}$ ratio (bpm/mmHg) for reflex bradycardia and reflex tachycardia, and 2) the linear regression slope $(\mathrm{ms} / \mathrm{mmHg})$ was determined by fitting changes in PI/ changes in MAP. Two different coefficients were calculated, one representing the reflex bradycardia and the other the reflex tachycardia. Only rats that presented a linear correlation between MAP and PI higher than 0.75 were considered in the study.

The Bezold-Jarisch reflex was stimulated by $i v$ injection of 5 doses $(2,4,8,16$, and $32 \mu \mathrm{g} / \mathrm{kg}$ ) of serotonin (5-HT; Sigma, St. Louis, MO, USA) given in a random sequence. All dose-response curves were plotted as percent changes in MAP or HR.

Stimulation of the peripheral chemoreceptors was obtained by means of cytotoxic hypoxia induced by bolus injection of potassium cyanide (KCN, $140 \mu \mathrm{g} / \mathrm{kg}$; Merck, Darmstadt, Germany). Literature data have demonstrated that KCN produces an appropriate activation of the peripheral chemoreceptors in rats $(15,16)$. Cardiovascular responses to peripheral chemoreflex activation were evaluated by percent changes in MAP and HR from basal values.

\section{Statistical analysis}

Data are reported as means \pm SEM. The paired Student $t$-test was used to compare basal MAP and HR before and after the administration of amiodarone or vehicle in each group. Cardiovascular reflex responses were compared between vehicle and amiodarone administration in normotensive and $1 \mathrm{~K} 1 \mathrm{C}$ hypertensive rats as follows: the effect of amiodarone, or vehicle, on baroreflex and arterial chemoreflex sensitivity was evaluated by the non-parametric Mann-Whitney test, while changes in the sensitivity of the Bezold-Jarisch reflex were assessed by repeated measures two-way analysis of variance, followed by the post hoc Tukey test for multiple comparisons. Differences were considered significant when $\mathrm{P}<0.05$.

\section{Results}

\section{Effects of amiodarone on basal HR and MAP}

Table 1 shows the HR and MAP data for normotensive and $1 \mathrm{~K} 1 \mathrm{C}$ hypertensive rats before and after amiodarone or vehicle administration. 1K1C hypertensive rats exhibited a higher basal MAP but similar basal HR compared to normotensive rats. Amiodarone produced similar reductions in HR in normotensive $(-17 \pm 2 \%)$ and $1 \mathrm{~K} 1 \mathrm{C}$ hypertensive $(-13 \pm 5 \%)$ rats. Besides bradycardia, amiodarone also caused a decrease in MAP in normotensive and $1 \mathrm{~K} 1 \mathrm{C}$ hypertensive rats. The hypotensive effect of amiodarone was significantly higher in $1 \mathrm{~K} 1 \mathrm{C}$ hyper- 
tensive rats $(-22 \pm 2 v s-10 \pm 1 \%$ in normotensive group). Vehicle administration did not change HR or MAP in either normotensive or $1 \mathrm{~K} 1 \mathrm{C}$ hypertensive animals.

\section{Effects of amiodarone on baroreflex sensitivity}

Baroreflex index. Amiodarone caused a reduction of baroreflex sensitivity for both reflex bradycardia and tachycardia in normotensive rats compared to vehicle (Figure 1). The reflex bradycardia and tachycardia were similarly attenuated by amiodarone, i.e., approximately $50 \%$.

Figure 1 also shows that $1 \mathrm{~K} 1 \mathrm{C}$ hypertensive rats presented an attenuated reflex bradycardia and tachycardia compared to normotensive rats. Amiodarone caused an additional attenuation of both reflex responses in $1 \mathrm{~K} 1 \mathrm{C}$ hypertensive rats, with the reflex bradycardia displaying greater attenuation $(67 \%)$ than tachycardia (39\%).

\section{Linear regression}

Figure 2 shows that the linear regression slope between changes in PI and MAP (ms/ $\mathrm{mmHg}$ ) corresponding to reflex bradycardia and reflex tachycardia was greatly attenuated by amiodarone in normotensive rats. In
$1 \mathrm{~K} 1 \mathrm{C}$ hypertensive rats amiodarone induced further attenuation of baroreflex sensitivity only in reflex bradycardia (Figure 2).

\section{Effects of amiodarone on the Bezold-Jarisch reflex}

Intravenous injection of 5-HT induced dose-dependent reflex mediated reductions in MAP and HR. The response pattern of the Bezold-Jarisch reflex was similar in normotensive and 1K1C hypertensive rats (Figure 3). Amiodarone attenuated the bradycardia (lower left panel) and hypotension (upper left panel) elicited by doses of 5-HT higher than $4 \mu \mathrm{g} / \mathrm{kg}$ compared to vehicle. The same response pattern was observed in $1 \mathrm{~K} 1 \mathrm{C}$ hypertensive rats treated with amiodarone (lower and upper right panels).

\section{Effects of amiodarone on the peripheral chemoreflex}

Intravenous injections of $\mathrm{KCN}$ produced peripheral chemoreceptor-mediated hypertension and bradycardia. Figure 4 shows the magnitude of the reflex changes in MAP and $\mathrm{HR}$ elicited by $\mathrm{KCN}$ in normotensive and $1 \mathrm{~K} 1 \mathrm{C}$ hypertensive rats treated with vehicle or amiodarone. In normotensive rats the hypertensive response (upper left columns) did

Table 1. Heart rate (HR) and mean arterial pressure (MAP) before (baseline) and 20 min after intravenous administration of $50 \mathrm{mg} / \mathrm{kg}$ amiodarone to normotensive and chronic one-kidney, one-clip (1K1C) hypertensive rats.

\begin{tabular}{|c|c|c|c|c|c|c|}
\hline & \multicolumn{3}{|c|}{ MAP (mmHg) } & \multicolumn{3}{|c|}{ HR (bpm) } \\
\hline & Before & After & & Before & After & \\
\hline \multicolumn{7}{|c|}{ Normotensive rats } \\
\hline Vehicle & $105 \pm 4$ & $100 \pm 3$ & $(-4 \pm 2 \%)$ & $335 \pm 8$ & $348 \pm 7$ & $(4 \pm 2 \%)$ \\
\hline Amiodarone & $104 \pm 3$ & $94 \pm 3^{*}$ & $(-10 \pm 1 \%)$ & $341 \pm 8$ & $287 \pm 7^{*}$ & $(-17 \pm 2 \%)$ \\
\hline \multicolumn{7}{|c|}{ Hypertensive $(1 \mathrm{~K} 1 \mathrm{C})$ rats } \\
\hline Vehicle & $191 \pm 7^{+}$ & $196 \pm 11$ & $(2 \pm 3 \%)$ & $368 \pm 8$ & $375 \pm 14$ & $(2 \pm 3 \%)$ \\
\hline Amiodarone & $174 \pm 8^{+}$ & $134 \pm 4^{*}$ & $(-21 \pm 3 \%)$ & $333 \pm 13$ & $278 \pm 10^{*}$ & $(-11 \pm 6 \%)$ \\
\hline
\end{tabular}

Data are reported as means \pm SEM for 9 to 11 rats in each group.

${ }^{*} \mathrm{P}<0.05$ versus respective baseline (paired Student $t$-test); ${ }^{+} \mathrm{P}<0.05$ vs baseline of the normotensive group (Student $t$-test). 

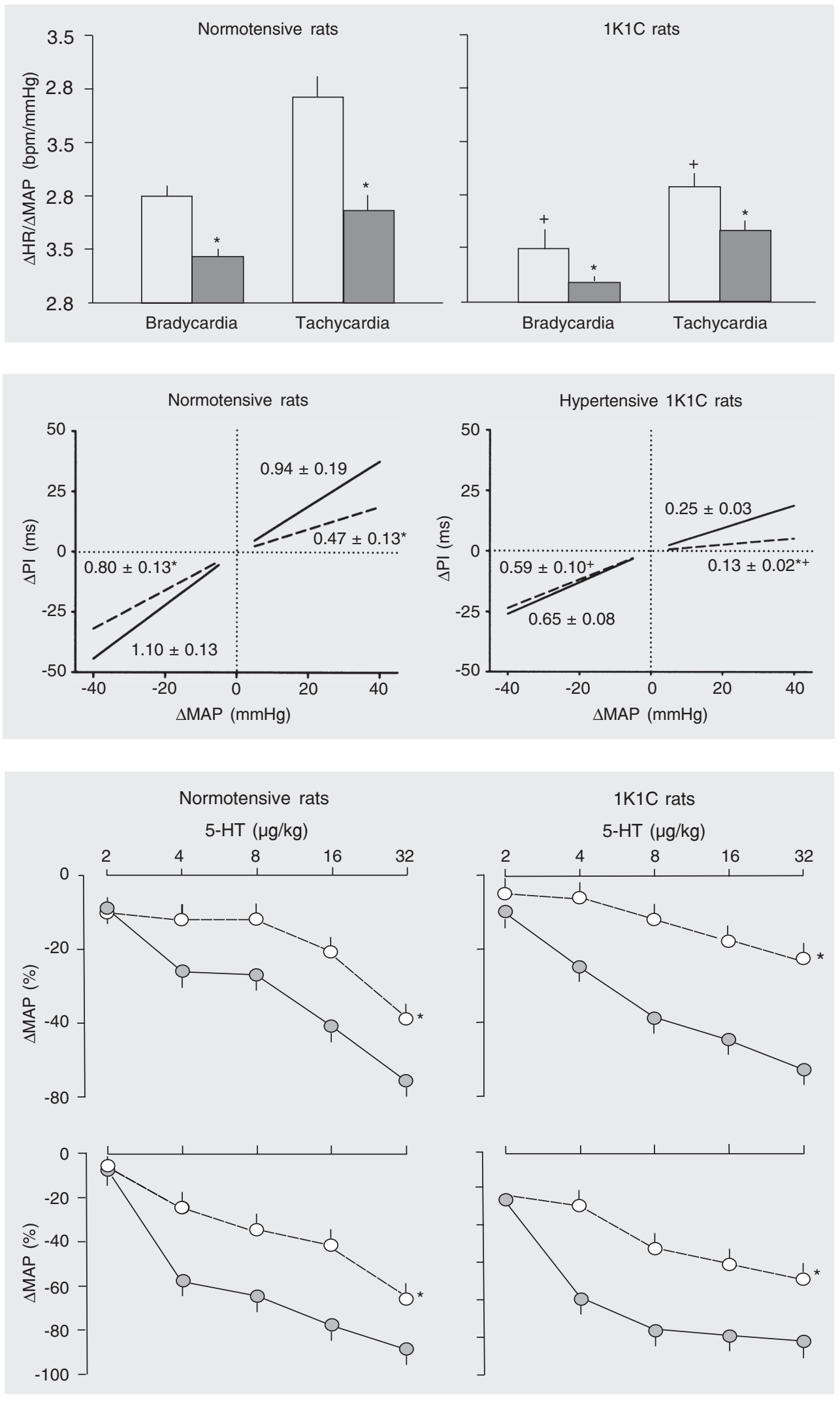

Figure 1. Baroreflex sensitivity evaluated by means of the heart rate/mean arterial pressure $(\triangle \mathrm{HR} / \Delta \mathrm{MAP})$ ratio for reflex bradycardia and reflex tachycardia in normotensive rats (left panel) and chronic one-kidney, oneclip (1K1C) hypertensive rats (right panel) treated with $50 \mathrm{mg} / \mathrm{kg}$ amiodarone (filled columns) or vehicle (open columns). Data are reported as means \pm SEM for 9 to 11 rats in each group. ${ }^{*} \mathrm{P}<0.05$ vs vehicle; ${ }^{+} \mathrm{P}$ $<0.05$ vs normotensive rats treated with vehicle (non-parametric MannWhitney test).

Figure 2. Baroreflex sensitivity (ms/ $\mathrm{mmHg}$ ) evaluated by means of linear regression for reflex bradycardia and reflex tachycardia in normotensive (left panel) and chronic onekidney, one-clip (1K1C) hypertensive rats (right panel) treated with vehicle (solid lines) or $50 \mathrm{mg} / \mathrm{kg}$ amiodarone (dashed lines). The slope of each linear regression (baroreflex gain) is reported as the mean \pm SEM for 9 to 11 rats. MAP = mean arterial pressure; $\mathrm{PI}=$ pulse interval. ${ }^{*} \mathrm{P}<0.05$ vs vehicle; ${ }^{+} \mathrm{P}<$ 0.05 vs normotensive rats treated with vehicle (non-parametric MannWhitney test).

Figure 3. Dose-response curves showing the reflex changes in mean arterial pressure ( $\triangle \mathrm{MAP}, \%)$ and heart rate $(\Delta \mathrm{HR}, \%)$ in response to $2,4,8,16$, and $32 \mu \mathrm{g} / \mathrm{kg}$ 5-hydroxytryptamine (5-HT) in normotensive (left panels) and chronic one-kidney, one-clip (1K1C) hypertensive rats (right panels) treated with vehicle (filled circles) or $50 \mathrm{mg} / \mathrm{kg}$ amiodarone (open circles). Data are reported as means \pm SEM for 9 to 11 rats in each group. ${ }^{*} \mathrm{P}<0.05$ vs vehicle (repeated measures twoway analysis of variance). 
Figure 4. Changes in mean arterial pressure $(\triangle \mathrm{MAP}, \%)$ and heart rate $(\Delta \mathrm{HR}, \%)$ in response to chemoreflex activation with $140 \mu \mathrm{g} / \mathrm{kg} \mathrm{KCN}$ in normotensive and chronic one-kidney, one-clip (1K1C) hypertensive rats treated with vehicle (open columns) or $50 \mathrm{mg} / \mathrm{kg}$ amiodarone (filled columns). Data are reported as means \pm SEM for 9 to 11 rats in each group. ${ }^{*} P<0.05$ vs vehicle (non-parametric Mann-Whitney test).

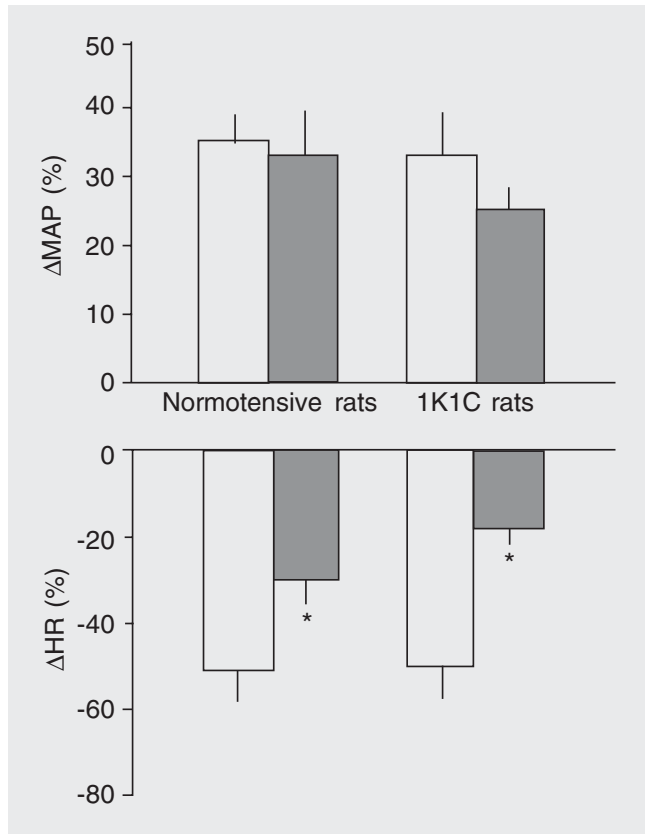

not differ between vehicle and amiodarone, while bradycardia (lower left columns) was attenuated by amiodarone. Similarly, in $1 \mathrm{~K} 1 \mathrm{C}$ hypertensive rats amiodarone caused no change in the hypertensive response (upper right columns), but caused attenuation of the reflex bradycardia (lower right columns). Again, it is noteworthy that the same response pattern of the peripheral chemoreflex was similar in normotensive and $1 \mathrm{~K} 1 \mathrm{C}$ hypertensive rats.

\section{Discussion}

The present study reports, for the first time, that the Bezold-Jarisch reflex and the peripheral chemoreceptor reflex were attenuated by acute administration of amiodarone in either normotensive or $1 \mathrm{~K} 1 \mathrm{C}$ hypertensive rats. The arterial baroreflex was also impaired by acute amiodarone administration. In addition, the reflex control of HR in $1 \mathrm{~K} 1 \mathrm{C}$ hypertensive rats was further attenuated by amiodarone. Since the reflex control of the circulation is very important for the maintenance of circulatory homeostasis, these findings deserve careful examination because acute administration of amiodarone is commonly used in clinical conditions such as myocardial infarction, which usually involve autonomic disturbances and altered cardiovascular reflexes (5).

\section{Hemodynamic effects of amiodarone}

Amiodarone elicited similar bradycardia (about 15\%) in normotensive and $1 \mathrm{~K} 1 \mathrm{C}$ hypertensive rats. Bradycardia caused by iv infusion of this antiarrhythmic drug has also been observed in humans (17) and rats (9). The negative chronotropic effect induced by amiodarone has been attributed to its depressant effect on the sinus node involving blockade of $\mathrm{Ca}^{2+}$ L-type channels $(18,19)$, prolongation of the action potential and/or reduction of the slope of the diastolic depolarization (20). Besides its direct effect on the sinus node, amiodarone elicits bradycardia which may result from the non-competitive ß-adrenergic blockade and/or reserpine-like sympatholytic action of the drug (4). Another hypothesis to explain the effect of amiodarone on HR is the direct effect of the drug stimulating vagal activity (8). Dias da Silva et al. (9) used spectral analysis to examine HR variability and reported that acute administration of amiodarone was associated with a significant increase in the magnitude of respiratory sinus arrhythmia, a widely recognized marker of vagal modulation of the heart (21). Moreover, recordings of efferent vagal and sympathetic activities revealed an increase in vagal activity and a decrease in the sympathetic discharge after $i v$ administration of amiodarone to decerebrate unanesthetized rats (8).

The hypotensive effect of $i v$ amiodarone has been described previously in humans (7) and rats (22) and has been attributed mainly to peripheral vasodilatation, which may be associated with different mechanisms such as a reserpine-like sympatholytic vascular effect (4), an $\alpha$-adrenergic-blocking action (23), or activation of nitric oxide and cyclooxygenase pathways (24). In addition, a di- 
rect effect on vascular smooth muscle cells due to the $\mathrm{Ca}^{2+}$ channel-blocking properties of amiodarone (2) cannot be ruled out. Regarding the hemodynamic effects of amiodarone, a decreased cardiac contractility (25) may also play a role in this hypotensive effect. Likewise, higher doses of amiodarone elicited vasodilatation of human veins (24), an effect which decreases the cardiac preload, causing hypotension. The hypotensive effect of amiodarone was larger in $1 \mathrm{~K} 1 \mathrm{C}$ hypertensive rats compared to normotensive rats. Even though $1 \mathrm{~K} 1 \mathrm{C}$ hypertensive rats exhibited a higher basal MAP, a sympathetic overactivity of this hypertensive model (11) supports the notion that the greater hypotensive response involves a sympatholytic effect of amiodarone $(4,9)$.

\section{Effect of amiodarone on cardiovascular reflexes}

The present study shows that amiodarone caused attenuation of the baroreflex, Bezold-Jarisch reflex and bradycardia of the chemoreflex in both normotensive and $1 \mathrm{~K} 1 \mathrm{C}$ hypertensive rats. The cardiac baroreflex gain is determined by the slope of the linear regression fitted through the reflex changes of pulse interval due to pharmacologically induced changes in MAP. Baroreceptor reflex sensitivity can also be evaluated as the $\triangle \mathrm{HR} / \Delta \mathrm{MAP}$ ratio and is reported as the index for baroreflex sensitivity. Both approaches allow separate assessment of the gain for the bradycardic and tachycardic responses, and were used in the present study to separately evaluate the reflex control of HR (26). For a better appreciation of the cardiac baroreflex sensitivity, in the present study we used linear regression as well as the baroreflex index.

Evaluation of baroreflex sensitivity indicated that both reflex bradycardia and tachycardia were attenuated by acute administration of amiodarone in normotensive rats. Rats with renovascular hypertension exhibit a depressed reflex control of HR which has been extensively demonstrated in the literature $(27,28)$. Nevertheless, amiodarone induced a further attenuation of the reflex bradycardia and tachycardia on the basis of the baroreflex index in $1 \mathrm{~K} 1 \mathrm{C}$ hypertensive rats. However, when baroreflex sensitivity was examined by linear regression, $1 \mathrm{~K} 1 \mathrm{C}$ hypertensive rats displayed a significant attenuation solely of the reflex bradycardia. There is no reasonable explanation for the discrepancy in the results observed by the two methods. Although amiodarone led to a 10 to $20 \%$ decrease in MAP and HR levels, the attenuation of baroreflex sensitivity was clearly seen by both approaches used. The present finding that amiodarone attenuated the reflex control of HR, obtained by means of the baroreflex index in normotensive and 1K1C hypertensive rats, does not confirm previous observations in normotensive Wistar-Kyoto rats and SHR (9), since in these models amiodarone produced an increase of baroreflex sensitivity. A possible explanation for these contradictory results can be ascribed to differences in the methodological approaches. While Dias da Silva et al. (9) reached their conclusions on the basis of spectral analysis, in the present study the baroreflex index and linear regression were used. The mechanism involved in the attenuation of the baroreflex induced by amiodarone may be related to the electrophysiological actions of this drug on the heart. In vitro studies have shown that amiodarone inhibits the acetylcholine-dependent $\mathrm{K}^{+}$current $(1,29)$. Thus, reflex vagal activation in response to a rise in AP may not be evident in the heart due to the blockade of the acetylcholine-dependent $\mathrm{K}^{+}$current by amiodarone. On the other hand, taking into consideration the noncompetitive $\beta$-adrenergic blockade and reserpine-like sympatholytic action of amiodarone, the reflex sympathetic activation in response to a fall in AP might be masked by this antiarrhythmic drug. Therefore, the attenuation of the baroreflex sensi- 
tivity induced by amiodarone may result from a lower responsiveness of the sinus node to sympathetic and parasympathetic modulation. This hypothesis agrees with previous observations that amiodarone attenuated not only the vagal, but also the sympathetic effects on the sinus node of rabbits (30). Furthermore, in 1K1C hypertensive rats, $i v$ amiodarone seems to affect the vagal modulation more strongly than the sympathetic modulation. Accordingly, we suggest that the overactivity of the sympathetic system in hypertensive states may counterbalance the lower responsiveness of the sinus node to sympathetic modulation induced by amiodarone, resulting in a smaller attenuation of the reflex tachycardia than of the reflex bradycardia.

Amiodarone induced less hypotension and reflex bradycardia during the activation of the Bezold-Jarisch reflex in both normotensive and $1 \mathrm{~K} 1 \mathrm{C}$ hypertensive rats compared with vehicle-treated controls. $1 \mathrm{~K} 1 \mathrm{C}$ hypertensive rats did not present an impairment of the Bezold-Jarisch reflex compared to normotensive rats. This finding is consistent with studies that demonstrated a preserved cardiopulmonary reflex in SHR (31, 32). A hypothesis to explain the attenuation of the bradycardia of the Bezold-Jarisch reflex induced by amiodarone may also take into consideration the electrophysiological effects of this drug involving acetylcholinedependent $\mathrm{K}^{+}$current blockade and a lower responsiveness of the sinus node to vagal activation. The hypotensive response of the Bezold-Jarisch reflex was also attenuated by amiodarone in both normotensive and $1 \mathrm{~K} 1 \mathrm{C}$ hypertensive rats. Since amiodarone seems to block the electrophysiological mechanisms involved in vagal modulation of the heart (30) it is reasonable to suggest that the lower hypotensive response could be a consequence of the attenuated bradycardia.

It is well known that the reflex bradycardia due to peripheral chemoreflex stimulation with $\mathrm{KCN}$ is mediated by vagal activa- tion (33). A similar hypothesis involving the electrophysiological effects of amiodarone could also explain the attenuation of the bradycardia induced by amiodarone in normotensive and $1 \mathrm{~K} 1 \mathrm{C}$ hypertensive rats.

The hypertensive response to peripheral chemoreflex activation was not affected by the administration of amiodarone. It is known that the pressor response of the peripheral chemoreflex is caused by sympathetic activation, which promotes peripheral vasoconstriction (34). Although the literature $(4,9)$ and the findings of the present study suggest a vascular sympatholytic action of amiodarone, this mechanism was not able to blunt the pressor component of the chemoreflex. The reflex response to peripheral chemoreflex activation in $1 \mathrm{~K} 1 \mathrm{C}$ hypertensive rats did not differ from that found in normotensive rats, indicating that the peripheral chemoreflex is not affected in this chronic hypertensive state. This finding is consistent with reports of preserved peripheral chemoreflex in renal hypertensive rabbits (35) and SHR (36).

An effect of amiodarone within the central nervous system cannot be ruled out since amiodarone has been detected in the brain 20-30 min after iv administration to rats (14), even though there are no data describing a specific site for the action of amiodarone within the central nervous system. Moreover, a possible effect of amiodarone on the afferents of cardiovascular reflexes cannot be excluded, particularly because the literature lacks any information about such effect.

In agreement with previous observations in Wistar-Kyoto rats and SHR, the acute administration of amiodarone caused bradycardia and hypotension in both normotensive and $1 \mathrm{~K} 1 \mathrm{C}$ hypertensive rats. In addition, amiodarone attenuated baroreflex sensitivity, Bezold-Jarich reflex and bradycardia of the peripheral chemoreflex in both normotensive and $1 \mathrm{~K} 1 \mathrm{C}$ hypertensive Wistar rats. Thus, we suggest that the attenuation of the cardiovascular reflexes may be due to 
the electrophysiological effects of amiodarone impairing the autonomic control of the sinus node.

\section{Acknowledgments}

The authors acknowledge the technical assistance of Mauro de Oliveira and Jaci A. Castania.

\section{References}

1. Watanabe $Y$, Hara $Y$, Tamagawa M \& Nakaya H (1996). Inhibitory effect of amiodarone on the muscarinic acetylcholine receptor-operated potassium current in guinea pig atrial cells. Journal of Pharmacology and Experimental Therapeutics, 279: 617-624.

2. Nishimura M, Follmer CH \& Singer DH (1989). Amiodarone blocks calcium current in single guinea pig ventricular myocytes. Journal of Pharmacology and Experimental Therapeutics, 251: 650-659.

3. Kadish AH, Chen RF, Schmaltz S \& Morady F (1990). Magnitude and time course of beta-adrenergic antagonism during oral amiodarone therapy. Journal of the American College of Cardiology, 16: 1240-1245.

4. Du X-J, Esler MD \& Dart AM (1995). Sympatholytic action of intravenous amiodarone in the rat heart. Circulation, 91: 462-470.

5. Amiodarone Trials Meta-Analysis Investigators (1997). Effects of amiodarone on mortality after acute myocardial infarction, and in congestive heart failure: meta-analysis of individual data from 6500 patients in randomized trial. Lancet, 350: 1417-1424.

6. Hughes M \& Binning A (2000). Intravenous amiodarone in intensive care. Intensive Care Medicine, 26: 1730-1739.

7. Cheung AT, Weiss SJ, Savino JS, Levy WJ, Augoustides JG, Harrington A \& Gardner TJ (2003). Acute circulatory actions of intravenous amiodarone loading in cardiac surgical patients. Annals of Thoracic Surgery, 76: 535-541.

8. Dias da Silva VJ, Gnecchi-Ruscone T, Lavelli B, Bellina V, Manzella D, Porta A, Malliani A \& Montano N (2002). Opposite effects of intravenous amiodarone on cardiovascular vagal and sympathetic efferent activities in rats. American Journal of Physiology, 283: R543-R548.

9. Dias da Silva VJ, Viana PCC, Alves RM, Fazan Jr R, Ruscone TG, Porta A, Malliani A, Salgado HC \& Montano N (2002). Intravenous amiodarone modifies autonomic balance and increases baroreflex sensitivity in conscious rats. Autonomic Neuroscience: Basic and Clinical, 95: 88-96.

10. Seto S, Rabito SF, Scicli AG \& Carretero OA (1984). Lack of evidence for the participation of tonin in the pathogenesis of one kidney one clip hypertension. Circulation Research, 55: 580-584.

11. Brody MJ, Barron KW, Kathleen HB, Faber JE \& Rodney WL (1983). Neurogenic mechanisms of experimental hypertension. In: Genest J, Kuchel O, Hamet P \& Cantim M (Editors), Hypertension: Physiopathology and Treatment. Clinical Research Institute of Montreal, Montreal, Quebec, Canada.

12. Krieger EM, Salgado HC \& Michelini LC (1982). Resetting of the baroreceptors. International Review of Physiology, 26: 119-146.

13. Schaffenburg CA (1959). Device to control constriction of main renal artery for production of hypertension in small animals. Proceedings of the Society for Experimental Biology and Medicine, 101: 676-677.

14. Wyss PA, Moor MJ \& Bickel MH (1990). Single-dose kinetics of tissue distribution, excretion and metabolism of amiodarone in rats. Journal of Pharmacology and Experimental Therapeutics, 254: 502-
507.

15. Franchinni KG \& Krieger EM (1993). Carotid chemoreceptors influence arterial pressure in intact and aortic-denervated rats. American Journal of Physiology, 262: R677-R683.

16. Barros RC, Bonagamba LG, Okamoto-Canesin R, Oliveira M, Branco LG \& Machado BH (2002). Cardiovascular responses to chemoreflex activation with potassium cyanide or hypoxic hypoxia in awake rats. Autonomic Neuroscience: Basic and Clinical, 97: 110-115.

17. Munoz A, Karila $P$, Gallay $P$, Zettelmeier $F$, Messner $P$, Mery $M$ \& Grolleau R (1988). A randomized hemodynamic comparison of intravenous amiodarone with and without Tween 80. European Heart Journal, 9: 142-148.

18. Gloor HO, Urthaler F \& James TN (1983). Acute effects of amiodarone upon the canine sinus node and atrioventricular junctional region. Clinical Investigation, 71: 1457-1466.

19. Satoh H (1991). Class III antiarrhythmic drugs (amiodarone, bretylium and sotalol) on action potentials and membrane currents in rabbit sino-atrial node preparations. Naunyn-Schmiedeberg's Archives of Pharmacology, 344: 674-681.

20. Goupil N \& Lenfant J (1976). The effects of amiodarone on the sinus node activity of the rabbit heart. European Journal of Pharmacology, 39: 23-31.

21. Malliani A, Pagani M, Lombardi F \& Cerutti S (1991). Cardiovascular neural regulation explored in the frequency domain. Circulation, 84: 482-492.

22. Cough WB, Zeiler RH, Barreca P \& El-Sherif N (1982). Hypotensive action of commercial intravenous amiodarone and polysorbate 80 in dogs. Journal of Cardiovascular Pharmacology, 4: 375-380.

23. Bacq ZM, Blakeley AG \& Sumers RJ (1976). The effects of amiodarone, an alpha and beta-receptor antagonist, on adrenergic transmission in the cat spleen. Biochemical Pharmacology, 25: 1195-1199.

24. Grossmann M, Dobrev D \& Kirch W (1998). Amiodarone causes endothelium-dependent vasodilation in human hand veins in vivo. Clinical Pharmacology and Therapeutics, 64: 302-311.

25. Winslow E, Campbell JK \& Barron E (1990). Effects of amiodarone on cardiac electrophysiology and inducibility of arrhythmias in chronically infarcted dogs: late arrhythmias, haemodynamics, and sympatholytic actions. Journal of Cardiovascular Pharmacology, 16: 896-904.

26. Farah VMA, Moreira ED, Pires MD, Irigoyen MCC \& Krieger EM (1999). Comparison of three methods for the determination of baroreflex sensitivity in conscious rats. Brazilian Journal of Medical and Biological Research, 32: 361-369.

27. Moyses MR, Cabral AM, Marcal D \& Vasquez EC (1994). Sigmoidal curve fitting of baroreceptor sensitivity in renovascular 2K1C hypertensive rats. Brazilian Journal of Medical and Biological Research, 27: 1419-1424.

28. Howe PRC, Rogers PF \& Head GA (1989). Limited baroreflex 
control of heart rate in young stroke-prone spontaneously hypertensive rats. Journal of Hypertension, 7: 69-75.

29. Guillemare E, Marion A, Nisato D \& Patrick G (2000). Inhibitory effects of dronedarone on muscarinic $\mathrm{K}^{+}$current in guinea pig atrial cells. Journal of Cardiovascular Pharmacology, 36: 802-805.

30. Murthy VS \& Hwang TF (1986). Antiarrhythmic drugs and the modulation of autonomic control of heart rate in rabbits. Federation Proceedings, 45: 2186-2190.

31. Ricksten SE \& Thoren P (1980). Reflex inhibition of sympathetic activity during volume load in awake normotensive and spontaneously hypertensive rats. Acta Physiologica Scandinavica, 110: 7782.

32. Ricksten SE, Noresson E \& Thorén P (1979). Inhibition of renal sympathetic nerve traffic from cardiac receptors in normotensive and SHR. Acta Physiologica Scandinavica, 106: 17-22.
33. Haibara AS, Colombari E, Chianca DA, Bonagamba LG \& Machado BH (1995). NMDA receptors in NTS are involved in bradycardic but not in pressor response of chemoreflex. American Journal of Physiology, 269: H1421-H1427.

34. Urbanski RW \& Sapru HN (1988). Evidence for a sympathoexcitatory pathway from the nucleus tractus solitarii to the ventrolateral medullary pressor area. Journal of the Autonomic Nervous System, 23: $161-174$

35. Angell-James JE, Clarke JA, Daly MD \& Taton A (1985). Respiratory and cardiovascular responses to hyperoxia, hypoxia and hypercapnia in the renal hypertensive rabbit; role of carotid body chemoreceptors. Journal of Hypertension, 3: 213-223.

36. Hayward LF, Johnson AL \& Felder RB (1999). Arterial chemoreflex in conscious normotensive and hypertensive adult rats. American Journal of Physiology, 276: H1215-H1222. 